\title{
HR'S FUTURE ON THE WAY TO A PRESENCE
}

\section{Wayne Brockbank}

\section{Introduction}

The business context within which human resource (HR) departments function is mandating new agendas, activities, and results. Emerging contextual factors such as information technology and globalization require that HR assume new agendas and practices. In this paper, these contextual factors will be examined; the emerging focal agendas of $\mathrm{HR}$ will be discussed; and the emerging list of HR practices will be briefly reviewed.

\section{Emerging Contexts}

The radical changes in the environment context have been well documented (Stacey, 1992; Hamel \& Prahalad, 1994; Drucker, 1995; Goldman, Nagel, \& Preiss, 1995). The future context of business will be characterized by greater numbers of competitors, customer consolidation, consolidation of stock ownership, undersupply of skilled labor, increasingly interdependent process technologies, multifunctional product technologies, a large service sector, and lower customer-based switching costs. Each of these will have implications for future HR agendas and practices. The two emerging contextual factors which will have the greatest influence on the conceptualization and execution of HR agendas, however, are information technology and globalization.

\section{Information Technology}

Rapidly emerging information technology has enabled the gathering, consolidating and dis- seminating of information as never before thereby making possible the involvement in decision making of individuals who are closest to the work itself (D'Aveni, 1994). To obtain the benefits of such information dispersion companies must train individuals in utilizing information in decision making, provide incentives for their involvement in decision making, and formally authorize their involvement in decision making. Well-informed, welltrained, and properly motivated workers allow spans of control to be expanded and layers of management to be reduced. Companies may thus reap the benefits of lower management costs and more responsive and informed decision making.

\section{Globalization}

As a function of reduced transportation and information costs and of the removal of social and political barriers, the globalization of business is proceeding at unprecedented and unexpected rates. The opening up of markets and competitors in countries such as China, Russia, and India places competitive pressures on virtually every major industry. Four implications for HR may be delineated. First, both the criteria and intensiveness of competition are changing as a result of globalization. Cost pressures increase along with demands for greater speed, quality, and innovation. Faced with this competitive environment, companies are asking their employees for more time, more commitment, and greater intensity. Second, as the labor force becomes increasingly global, pressures mount for greater adaptation to and accommodation for local conditions.
The two emerging contextual factors which will have the greatest influence on the conceptualization and execution of $\mathrm{HR}$ agendas, however, are information technology and globalization. 
Emerging HR agendas embody the strategic intent for the HR function and differ from $H R$ practices in several important ways.
Concurrently, many employees in the emerging competitive countries are accustomed to considerable government protection and to locally defined competitive criteria. HR must tailor its policies and practices to local conditions while at the same time modifying the mindset and technical skills of local employees to world class standards. Third, the identification and development of leaders who are capable of functioning on a global scale and with a global perspective become a critical issue. While the dimensions of effective global leadership may reflect those of effective domestic leadership, their relative importance and operational application vary substantially. Our knowledge of effective global leadership pales in comparison to our knowledge of effective domestic leadership. The depth of a firm's global leadership capability is emerging as a major enabler of global growth (Prahalad \& Doz, 1987). Fourth, one important criterion for the functioning of global leaders is achieving optimal organizational synergy. In the same vein, it is also HR's responsibility to design HR processes which encourage the organizational functioning so that the "global whole" is greater than the sum of the parts (Egelhoff, 1988). HR is in the early phases in its ability to conceptualize and impact this agenda.

\section{Emerging Agendas}

The emerging contextual conditions of business will create pressures for HR to add greater strategic value. Emerging HR agendas embody the strategic intent for the HR function and differ from HR practices in several important ways. Agendas are long term, have broad impact, and set the criteria for practices; HR practices, on the other hand, tend to be short-term, relatively narrow, and designed within the conceptual logic of the HR agenda. Several of the emerging agendas which will reflect a more strategic perspective of $\mathrm{HR}$ are as follows.

\section{Earning a Place at the Table}

Before strategic HR agendas can be brought to the strategy table, senior management has to perceive that HR has "earned a place at the table." Earning that place at the table is a function of many factors including the following: knowing the strategy, culture, vocabulary, and operating issues of the business; having passion for issues which add greatest value to external customers and shareholders; and focusing on financial results. Earning a place at the table also requires a track record of keeping the HR house in order. As HR assumes the more strategic role of creating sustained competitive advantage, it must first ensure that tactical HR activities are fully aligned with the short-term business strategies and that the tactical activities are completed with fewer resources but at higher quality levels. In providing short term tactical support, HR must ensure that: (1) the right people are being hired, promoted, transferred, and fired; (2) measures and rewards are aligned with short term business results; and (3) individual employees have the technical knowledge to achieve short term objectives.

\section{Conceptualizing the Value of People}

HR must ensure that senior management has grasped the idea that people are the critical and ultimate source of competitive advantage. In a competitive, changing market environment, executives are quickly learning that the human side of the business can be their best friend or their worst enemydepending on how the human and organizational issues are managed. We live in an era in which technologies and strategies can be imminently replicated; infrastructure capacity can be transferred; and switching costs are continually decreasing. Under such conditions, competitive advantage resides in a human organization which can (1) develop new technologies; (2) implement strategies more quickly, more efficiently, and more accurately; (3) improve operating technologies; and (4) constantly adjust to customers changing buying habits. Some companies are just now discovering and formalizing the "value of the human asset." These companies are probably a generation behind in their management though as leading companies have already embraced the centrality of people as competitive advantage and are aggressively utilizing the management and HR partnership in identifying and creating the technical and cultur- 
al capabilities which their people must have to win in the market place.

\section{Framing HR Strategy}

In the future HR departments will have to have an explicit, well-framed, and well-argued point of view; that is, they will have addressed the fundamental question of "What is the purpose of HR"? As rudimentary as this question may seem, most HR departments do not have an answer and, as a result, often lack a clear definition of what the members of the department are jointly trying to do. One exercise which may underscore the importance of this issue is to pose this question at the next HR staff meeting - "What is the purpose of HR?" Have each individual write down her/his answer. Compare the answers and discuss the implications. Each functional area within HR will probably have its respective individual purposes, but the department as a whole will not. If HR as a whole is unclear about its purpose, what can be expected from the rest of the company about the purpose of HR?

In developing a departmental point of view, the following criteria should be met. (1) Is it formally stated or is it ad hoc and assumed? (2) Does it create the short term technical knowledge and skills as well as the culture which is necessary to win over the long run? (3) Does it comprehensively cover the whole organization thereby encouraging the corporate whole to be greater than the sum of the parts? (4) Does it serve to integrate the various subfunctions within HR around commonly accepted principles or purposes? (5) Is it clearly linked to issues which are critical to long term corporate success including the present and future concerns of external customers and major shareholders? (6) Does it create explicit and measurable results?

\section{Framing Business Strategy}

Over the past few years a dominant paradigm in strategic thinking has been the concept of core competence (Hamel and Prahalad, 1994). The core competence of the firm is what the firm does best (given that what the firm does best is consistent with what customers want most). As an example, Hamel and
Prahalad cite the ability of Honda to design and manufacture internal combustion engines. The problem with framing core competence in terms of what the firm does best is that it condemns a firms' strategic thinking to a short term time perspective. The logic for this conclusion is as follows. What a firm does is based on what a firm knows. By framing core competence in terms of what a firm does, and what a firm does is based on what it knows, and given that the life span of knowledge is shrinking, core competence logic might channel strategic thinking into short time frames. Nevertheless, core competence framework is robustly useful. The key core competence, however, is not what a firm does based on what is known but is, rather, a firm having a culture which encourages flexibility, change, learning, creativity, and adaptability to customers. When reframed in this manner, the key issue is not core technical competencies but rather core cultural competencies. Given that a major responsibility of HR is defining and creating a competitive business culture, HR is at the heart of the leading paradigm in strategic thinking (Brockbank, 1995). The conclusion of this logic is that HR has an important role to play in the formulation of business strategy. To the strategy planning table, finance brings the available financial resources; the engineering department brings the available technological options; information systems folks bring internal information resources; and marketing brings customer information resources. To the strategy planning table HR should bring the inventory of technical knowledge and skills and, perhaps, more important an inventory of the firm's cultural strengths and weaknesses. HR should also bring a method for identifying the culture that the company needs to optimize market opportunities and a logic for creating the required competitive culture.

These two agendas are finding their way into the management paradigm of several well-managed firms such as American Express, Levi-Strauss, Disney, and Texas Instruments. Senior executives are recognizing that the managing by culture agenda has two directions of causality. They recognize that a culture must be created which is consistent with the business strategy, but they also recognize the value of creating a broadly and powerfully defined culture which is (1) strongly
The core competence of the firm is what the firm does best (given that what the firm does best is consistent with what customers want most).

HR should also bring a method for identifying the culture that the company needs to optimize market opportunities and a logic for creating the required competitive subculture. 
customer focused and (2) capable of leap-frogging the competition through continual and radical innovation. Having such a culture at their disposal creates strategic alternatives which would not otherwise be available. Thus HR becomes a major contributor to maximizing the firm's available strategic options.

\section{Promoting Growth}

During the past decade, many HR departments became highly skilled at downsizing and at other expressions of cost cutting. Undoubtedly these skills will continue to be required as HR fine-tunes its ability to create more strategically aligned workforces and as economic downturns again occur. The challenge which many companies are now embracing is top line growth. This poses new challenges for which many HR departments are less prepared.

The first step is to identify what is meant by growth: top line, bottom line, or market share. Most companies tend to define growth as some or all of the foregoing. Once growth is clearly defined, then the avenues of growth can be identified with accompanying cultural characteristics and avenues for creating these characteristics.

Four general avenues of growth may be delineated (Gertz \& Baptista, 1995). First, firms may grow within existing markets and with existing products either by buying the competition or by taking revenues away from the competition. Revenues may be taken from the competition by lowering costs, improving service or convenience, shortening delivery times, or improving product quality. HR's capacity to create business cultures through which these revenue-enhancing strategies are implemented can be a major source of competitive advantage. If a firm purchases a competitor, the HR challenge is to identify the culture which is required for both the acquiring firm and the acquired firm to be successful and to create unity in and between both firms on the basis of the culture which both need to succeed. The second avenue of growth is through existing products but within new markets (including global markets). The role of HR facilitating growth through this avenue, especially on a global scale is essential. Selecting the right local leadership, balancing local and corporate demands, and integrating the local units into a global entity-all are critical for success. Third, firms may also grow through new products within existing markets. The key to success in this avenue of growth is the creation of a business culture which emphasizes radical innovation as well as disciplined continuous improvement. The fourth avenue for growth is through new products and new markets. The HR role in this growth avenue is a combination of the above second and third categories.

\section{Responding to the Shareholders and Board Members}

An emerging HR agenda will be the responsibility of senior HR executives in building and maintaining credible relationships with key shareholders and board members. Since 1986 there has been a marked trend toward consolidation of stock ownership in publicly traded firms. This trend is the result of substantial growth in baby boomers' investments through pension funds and mutual funds (Business Week, March 15, 1993). Since baby boomers generally will not be taking money out of the financial markets until they begin to retire, the traditional short term focus of investment fund managers is changing so that they are not interested only in short term returns but also in long term performance. These "relational investors" are asking a new set of questions of senior management including the senior HR executive. What is the logic and process of your succession planning? Are incentive packages of senior executives linked to long term performance? What is the depth of the management team? Do you have the technological and cultural infrastructures which will allow the firm to compete over the long run? As a result of these directions of inquiry, HR executives find that they are spending more time with the senior line executive, with the board of directors, and occasionally with key shareholders discussing these and related questions.

\section{Emerging Practices}

As can be seen from the above discussion, the major component of the emerging HR agendas is the creation of the cultural mindset and technical competencies which are capable of winning in market place. A key challenge for 
HR is, therefore, to ensure that all of the practices which influence the technical and cultural capabilities of the firm are functioning in an integrated, focused, and mutually reinforcing manner. This challenge clearly expands the set of traditional HR practices. As these practices are reviewed, it will be clear that some are directly controlled by HR whereas others are only indirectly influenced by HR.

Those practices which generally are under the direct control of HR include the following: staffing practices including recruitment, promotions, transfers, and outplacement; performance management including measurement, and monetary and non-monetary rewards; and individual learning including formalized classroom training, on-the-job training, and ancillary developmental activities.

In addition to these traditional areas of HR involvement, other practices may have important influence on the human organization which HR may only indirectly influence. These areas include the following: structural concerns such as organization design, reengineering, job design, and the physical setting; practices which influence institution level learning such as external benchmarking, comprehensive customer contact programs, systemic internal communications, and informa- tion system design; and leadership decisions and actions which are held up to self-generated standards of consistency and integrity. It is HR's responsibility to ensure that all of these practices are integrated and aligned as they influence the creation of the ideal human organization. It is beyond the scope of this paper to describe the developments in each of these areas of present and future HR practices. Suffice it to say that compelling and powerful developments are occurring in the design and delivery of these broadly defined HR practices. This is especially compelling as these practices are designed within the perspective of the emerging HR agendas.

\section{Conclusion}

In summary the challenge for the HR professional is three fold: first, examine and understand the context which drives business realities; second, design critical, high value-added agendas; and, third, ensure that broadly defined HR practices are exactly aligned and unified around these agendas. As these develop, HR will contribute a more strategic and high value added presence as firms compete in increasingly complex and changing contextual conditions.

\section{A key challenge \\ for $H R$ is, therefore, to ensure that all of the practices which influence the technical and cultural capabili- ties of the firm are functioning in an integrated, focused, and mutually rein- forcing manner.}

WAYNE BrockBank is an Associate Professor of Business Administration at the Univer-
sity of Michigan Business School. He is the Faculty Director or Co-Director of the three
HR executive programs which were recently rated as the best HR executive programs in
the United States and Europe by the Wall Street Journal and Business Week. His current
research and publishing focus on (1) conceptual and process linkages between human re-
source practices and business strategy and (2) creating customer focused organizational
cultures. Professor Brockbank has consulted in these areas with many private corpora-
tions including Texas Instruments, Hewlett-Packard, General Motors, Citibank, Motoro-
la, and Cathay Pacific Airways.

\section{REFERENCES}

Brockbank, W. (1995). Logic and conflict and in corporate values. Paper presented at the Third International Conference on Social Values. Oxford University. Oxford, England.

Business Week (1993). Relationship investing. March 15.

D'Aveni, R.A. (1994). Hyper-Competition. New York: The Free Press

Drucker, P. (1995). Managing in a Time of Change. New York: Penguin Books.

Egelhoff, W.G. (1988). Organizing the Multinational Enterprise. Cambridge, MA: Ballinger Publishing Company.
Gertz, D.L., \& Baptista, J. (1995). Grow to be Great: Breaking the Downsizing Cycle. New York: Free Press.

Goldman, S.L., Nagel, R.N., \& Preiss, K. (1995). Agile Competitors and Virtual Organizations. New York: Van Nostrand Reinhold.

Hamel, G., \& Prahalad, C.K. (1994). Competing for the Future. Boston: Harvard Business School Press.

Prahalad, C.K., \& Doz, Y.L. (1987). the Multi-National Mission. New York: The Free Press.

Stacey, R.D. (1992). Managing the Unknowable. San Francisco: Jossey-Bass. 
